The Emerald City Solar Initiative partners included:

- Seattle City Light. The local municipally-owned electric utility, as program lead and contributor of the majority of funds to match the DOE Solar America Cities grant

- Northwest Sustainable Energy for Economic Development (Northwest SEED). A nonprofit contracted with Seattle City Light as a lead on education, outreach, and community solar program development

- Seattle Department of Planning and Development. A leader in permitting improvement processes and gap analysis of Seattle codes

- Office of Mayor Michael McGinn. A participant in team planning efforts

- Washington Department of Commerce. A contributor of matching funds and a resource for peer-exchange to share lessons with other Washington cities

- Bonneville Environmental Foundation. A promoter of outreach and education through Solar 4R Schools programs via a contract with Seattle City Light

- Seattle Department of Parks and Recreation. A site host for community solar demonstration projects and a host for solar workshops

- Pike Place Market Preservation and Development Authority. A potential community solar site host.

\section{Installed Capacity} Seattle

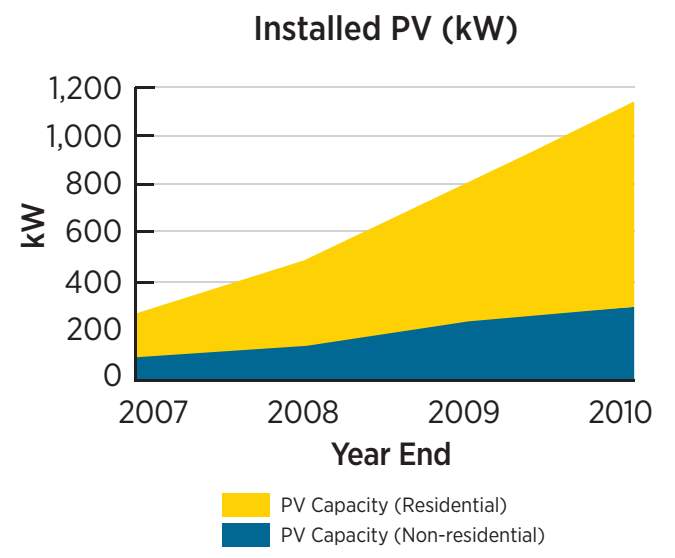

Installed PV capacity increase from December 31, 2007, to December 31, 2010

The Emerald City Solar Initiative set out to do the following:

- Incorporate solar energy evaluation and deployment into city planning efforts, including:

- Seattle's Neighborhood Plans

- Seattle's Green Building Program

- Seattle City Light's 5-Year Energy Efficiency Action Plan for the Conservation Resource Division

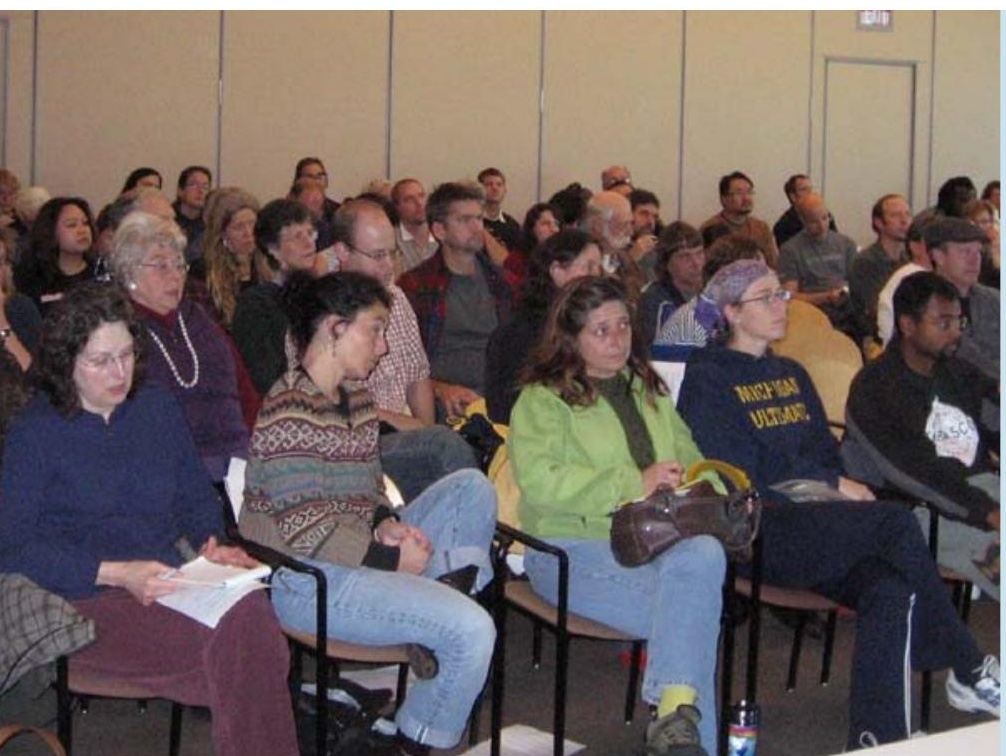

The Emerald City Solar Initiative workshops and training activities reached more than 1,000 residents, contractors, and code officials. Photo from Northwest Seed, NREL/PIX 19485 


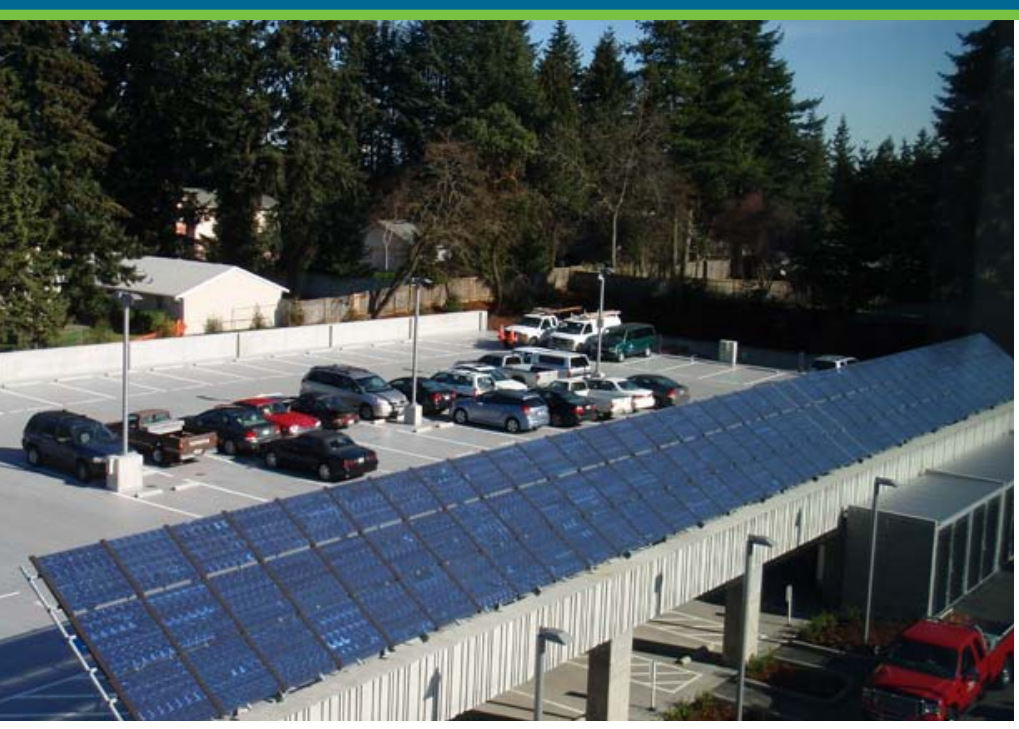

The City of Shoreline, Washington, installed a 20.2-kW solar electric system atop the City Hall parking garage. The system uses made-in-Washington solar modules from Marysville-based Silicon Energy and was installed by Shoreline-based Northwest Mechanical. Shoreline, just north of Seattle, is served by Seattle City Light. Photo from City of Seattle, NREL/PIX 18074

- Research and implement innovative financing mechanisms and ownership models to address the economic barriers to solar energy, including an ongoing and sustainable utility-led community solar program, as described in the case study on page 6

- Develop and implement education and outreach programs to Seattle City Light customers

- Evaluate and overcome barriers to interconnection in Seattle through:

- An audit and report on current interconnection practices

- Development of an interconnection guide and refined interconnection practices.

\section{Accomplishments and Highlights}

\section{City Planning}

- Developed a new Client Assistance Memo to help consumers understand the benefits of and process for installing PV and solar hot water systems. It is available online at www.seattle.gov/ DPD/Publications/CAM/cam420.pdf

- Conducted a full Gap Analysis of Seattle's codes and policies to recognize best practices encouraging solar energy use. This analysis included research on solar access policies, especially those that co-exist with tree canopy goals. The results are reported in "City of Seattle Code Review: Final Gap Analysis Report, February 9, 2010" (www.cityofseattle.net/Dclu/cms/groups/pan/@pan/@ sustainableblding/documents/web_informational/ dpdp018774.pdf)

- Developed a Small Renewables Action Plan for Seattle City Light, setting goals for installation targets and streamlining the customer experience.

\section{Innovative Financing}

- Completed a Community Solar Report detailing the opportunities available to the city and initiated a community solar program expected to launch in 2011

- Published the Northwest Community Solar Guide, authored by project partner Northwest SEED and Bonneville Environmental Foundation

- Participated in a rulemaking process for Washington SB 6170, which resulted in the ability for community solar program participants to take part in the state's solar production incentive program.

\section{Interconnection}

- Met with regional utilities, the Solar Electric Power Association, and regional solar contractors to seek input on desired improvements to Seattle's interconnection process

- Convened an interconnection task force to address gaps in interconnection standards, which resulted in a new department policy and procedure for interconnecting systems up to 20 megawatts (MW)

- Planned and held training workshops for utility staff.

\section{Education/Outreach}

- Developed a customer brochure "Solar Works in Seattle!" as well as led a series of workshops, described in the case study on page 5

- Organized and held the 2008 Seattle-Shoreline Solar Homes Tour featuring Solar Works presentations at three sites, as well as a drop-in tour of Seattle solar homes; more than 500 Seattle-area residents attended

- Organized and held the 2009 Seattle Solar Tour featuring 30 solar homes/businesses, in conjunction with the America Solar Energy Society National Solar Tour 
- Developed the "Consumer's Guide to Installing Solar," and updated Seattle City Light's solar website: www.seattle.gov/light/Conserve/cgen/cv5_cgen5.asp

- Helped revamp the website for Solar Washington (solarwa.org), the state chapter of America Solar Energy Society, which is instrumental in promoting solar and connecting customers with qualified contractors.

\section{Case Studies: Successes and Challenges}

\section{“Solar Works in Seattle!” Workshops}

Seattle City Light and Northwest SEED conducted a series of workshops aimed at homeowners considering installing solar systems on their houses. "Solar Works in Seattle!" workshops were conducted over 12 months. Content rotated between the following:

Solar Primer. A broad overview of solar electric and solar hot water, differences, opportunities, and incentives related to each.

\section{Solar Hot Water 101 and Solar Electricity 101. A more} in-depth explanation of the technology, how to work with the city (including permitting and interconnection), site evaluation, finding and working with a contractor, long-term issues, incentives, and economic evaluation.

Attendance at each workshop ranged from 50 to 80 people. The audience primarily was made up of residential customers, but some commercial customers, students, and installers also attended. An estimated 500 residents attended one or more of the workshops.

Workshops were free to the public and held at Seattle Department of Parks and Recreation community centers in various neighborhoods. The workshops gave Seattle City Light and Northwest SEED the opportunity to work with Parks and Recreation, a partnership that is continuing with a Community Solar installation in Jefferson Park.

The purpose of the workshops was not to convince the public to install solar but rather provide them with the tools necessary to analyze their property for a solar project. Workshops were deliberately kept unbiased and informational. Installers and vendors requested permission to have booths at workshops but were not allowed to do so. They were, however, welcome as attendees, and sometimes provided valuable perspective during question and answer periods.

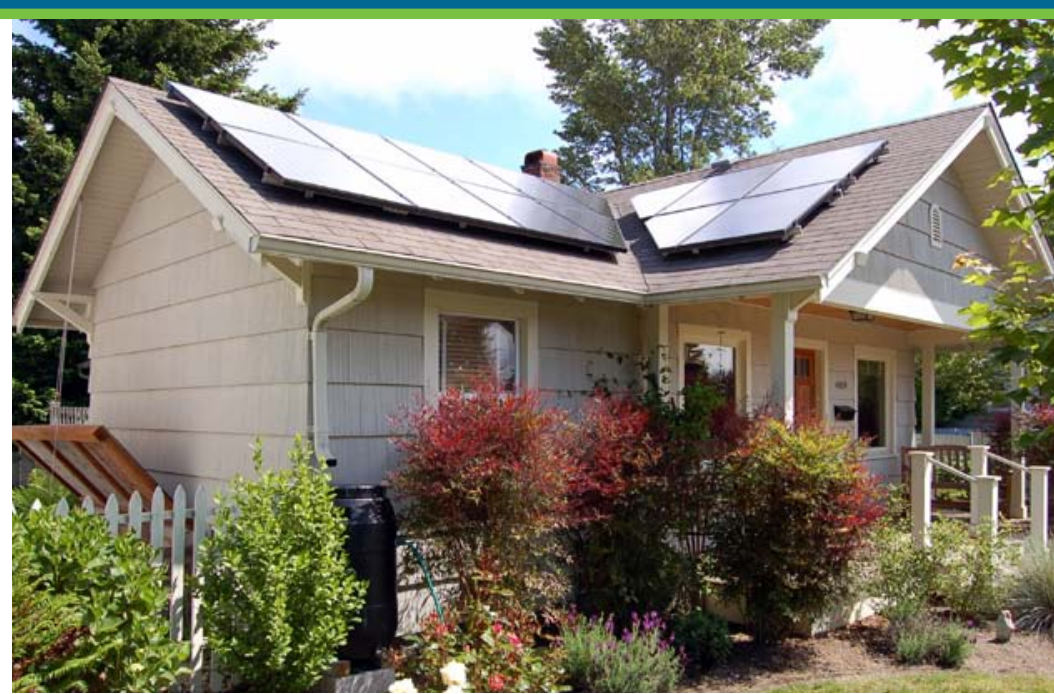

Residential solar installations often face shading issues in treefriendly Seattle; however, there is often a workable solution. Photo from Brothers Electric, NREL/PIX 19483

\section{Interconnection Training for Utility Staff}

As part of Seattle's Green Power Program, a solar demonstration project was installed on a commercial building in downtown Seattle. The project was small enough that it would not backfeed into the network, but due to the complexity of downtown area network grids, network engineers and field operations staff were uncomfortable interconnecting the installation.

Seattle City Light's Conservation Resources Division learned that the staff personnel involved in interconnecting the new project had concerns because they were unfamiliar with solar electric technology and did not know how the inverters and safety features functioned.

To address the concerns, a team including a representative from the Interstate Renewable Energy Council, a local solar installer, and Seattle City Light Renewables staff offered six workshops in October and November 2010. The workshops were tailored to divisions of field operators, engineers, meter technicians, and electrical service representatives (who work with customers submitting interconnection applications). Two workshops were open to all City Light staff, and addressed more general topics such as solar incentive programs and the trend of increasing customer interest in solar installations.

The training workshops were very well received by staff, and the demonstration project was successfully interconnected.

\section{Lessons Learned}

- Don't assume that everyone in a local government agency sees solar energy as a priority. Like many utilities, Seattle City Light supports solar energy generation, but its core mission is to provide uninterrupted power to its customers. Solar energy is not a primary concern in the daily work of 
most employees - it will require effort to engage other areas of the utility in solar projects.

- Persistence is necessary to get trainees in the room.

- It is necessary to get buy-in from staff as well as managers. The need for management buy-in may be obvious, but less obvious is the usefulness of strong support from the staff members who want the training. Staff members can help gain management support by passing their needs up through their management chains.

\section{"Community Solar" Financing Program Implementation}

The research and outreach conducted under the Emerald City Solar Initiative revealed two major barriers to solar in Seattle:

- High up-front cost

- Lack of solar access

To address these issues, the program partners were awarded a Solar America Cities special projects grant from DOE to create a community solar program sponsored by Seattle City Light that included a revolving fund to perpetuate future installations.

"Community solar" refers to solar electric systems owned by multiple community members who contribute to the cost of the system and receive a proportionate share of the power and/or financial benefit of the system. Community solar allows residents who would not otherwise be able to install solar on their homes (due to cost, location, or type of home) to participate in solar energy generation.

Seattle City Light took the following major steps in developing the community solar program:

\section{Developed Municipal Utility Community Solar Concept} for Seattle. Seattle City Light conducted market research to gauge receptivity to various community solar program models. Three focus groups were held to foster discussions about concerns and values related to solar energy use. These were followed by a phone survey of 500 customers to identify the levels of participation that might be expected for different program options. The phone survey determined that more than half of all potential community solar program participants would join a program at $\$ 600$ upfront, and that Seattle City Light was the most trusted entity to administer a community solar program. The survey also found that almost one in four ratepayers were "very interested" in a community solar option, and that the primary barrier was perceived cost.
Based on the market research, program planners at Northwest SEED and Seattle City Light created a concept for the utilityowned community solar program. The first installation would be funded by the DOE special projects grant, and the subsequent installations would be funded by customer enrollment fees.

2. Designed a Comprehensive Program. Program design drivers included:

- Legal issues, such as how to avoid Securities and Exchange Commission registration and how to conform to a utilityowned model, outlined in the Washington Renewable Energy Investment Cost Recovery (Production Incentive) program

- Customer demand and cost; specifically, determining the price point at which customers should be able to participate, and understanding whether or not equitable access to all Seattle City Light customers be could ensured

- Technical issues such as interconnecting in the downtown network grid

- Systems issues such as providing energy credits (or virtual net metering) with the existing Seattle City Light billing system.

The program design included development of a draft Customer Agreement (contract) and a process for enrollment and customer service. Terms of the Customer Agreement include:

- Customers pay a one-time, upfront payment for a Solar Unit— defined as the energy output associated with a pro-rata portion of the generation from a distinct solar array.

- Customers receive annual on-bill credits based on the energy credit.

- Participants can transfer their credits to a new account if they move.

- Seattle City Light will retire Renewable Energy Certificates on behalf of participants.

3. Selected the First Site. Program planners pursued a site at historic Pike Place Market, and obtained a system design in partnership with the Pike Place Development Authority. However, the Market Historical Commission's design review committee advised the planners that it would not approve any design that was visible to the public. A second site, at Jefferson Park, owned by the Seattle Department of Parks and Recreation, was selected and approved by all the necessary decision makers.

4. Completed Preliminary Installation Design. With technical assistance from the National Renewable Energy Lab, 
a local solar installer, a structural engineer, Seattle City Light, and the Seattle Department of Parks and Recreation, designed a Solar PV Picnic Shelter using solar modules as the roofing material. The design is modular, replicable, and will meet the needs of Seattle City Light as well as park-goers. The first community solar program installation will comprise three shelters (one $12-\mathrm{kW}$ shelter and two 6-kW shelters) for a total of $24 \mathrm{~kW}$.

The project is on track to be completed in 2011. Based on customer inquiries and community feedback, Seattle City Light anticipates that the 500 Solar Shares will be sold quickly.

\section{Lessons Learned}

- Historic properties present unique challenges for solar projects.

- When using grant money for construction, beware of conflicting federal, state, city, and local requirements.

- Community Solar should be promoted to at least two distinct constituencies: potential customers and neighborhood residents in the vicinity of an installation.

- Selecting a site and negotiating with the host can be much more time consuming than anticipated.

- Solar installations that include new structures or serve multiple purposes (such as the solar picnic shelters) are more expensive per watt of electric production than those that do not. However, these multi-use sites often make potential hosts more receptive.

\section{Top Takeaways}

- Residential customers are eager to learn about solar, and a well-designed workshop series can clear up many misconceptions.

- The city should educate service providers and customers. Utility employees need to understand the technology they handle and the services they provide to customers.

- Municipal utility customers are eager for solar options managed by the utility, and trust the utility to be the experts in solar development.
- It takes careful planning to design a community solar program that provides participants the opportunity to benefit from a solar purchase, while avoiding securities issues.

- An ideal community solar site - publicly accessible, highly visible, unshaded, and secure - can be difficult to find. Utility-owned community solar projects can be completed more quickly if the utility builds the system on property it owns. However, Seattle City Light chose to pursue installations that would be highly visible in the community. Program planners should consider the long-term goals of a community solar program when deciding where to site installations.

\section{Next Steps}

Seattle will start construction on its first community solar installation at Jefferson Park in 2011 in conjunction with other Seattle Department of Parks and Recreation improvement projects. According to the revolving funding and enrollment program design, and barring unforeseen delays from selecting new sites and subscribing new community solar customers, new installations could be commissioned each year on an ongoing basis. A Solar Site Evaluation intern has joined the team to help evaluate a broad range of community sites for the second and third installations.

Seattle City Light will continue to support its customers in going solar, be it through community solar models, volume purchasing scenarios, or other approaches.

\section{Additional Resources}

- Seattle City Light: www.seattle.gov/light/solar

- Solar Washington: http://solarwa.org/

- Northwest SEED: www.nwseed.org/

- "Guide to Community Solar": www.nrel.gov/docs/fy11osti/49930.pdf

For more city information, contact:

Jack Brautigam, Renewable Energy Program Manager, Seattle City Light Email: jack.brautigam@seattle.gov Telephone: 206-684-3954

For more information on going solar in your community, visit Solar Powering Your Community: A Guide for Local Governments at http://solaramericacommunities.energy.gov/resources/guide_for_local_governments/ 
Ann Arbor Austin Berkeley Boston Denver Houston Knoxville Madison Milwaukee Minneapolis-Saint Paul New Orleans New York Orlando Philadelphia Pittsburgh Portland Sacramento Salt Lake City San Antonio San Diego San Francisco San José Santa Rosa Seattle Tucson
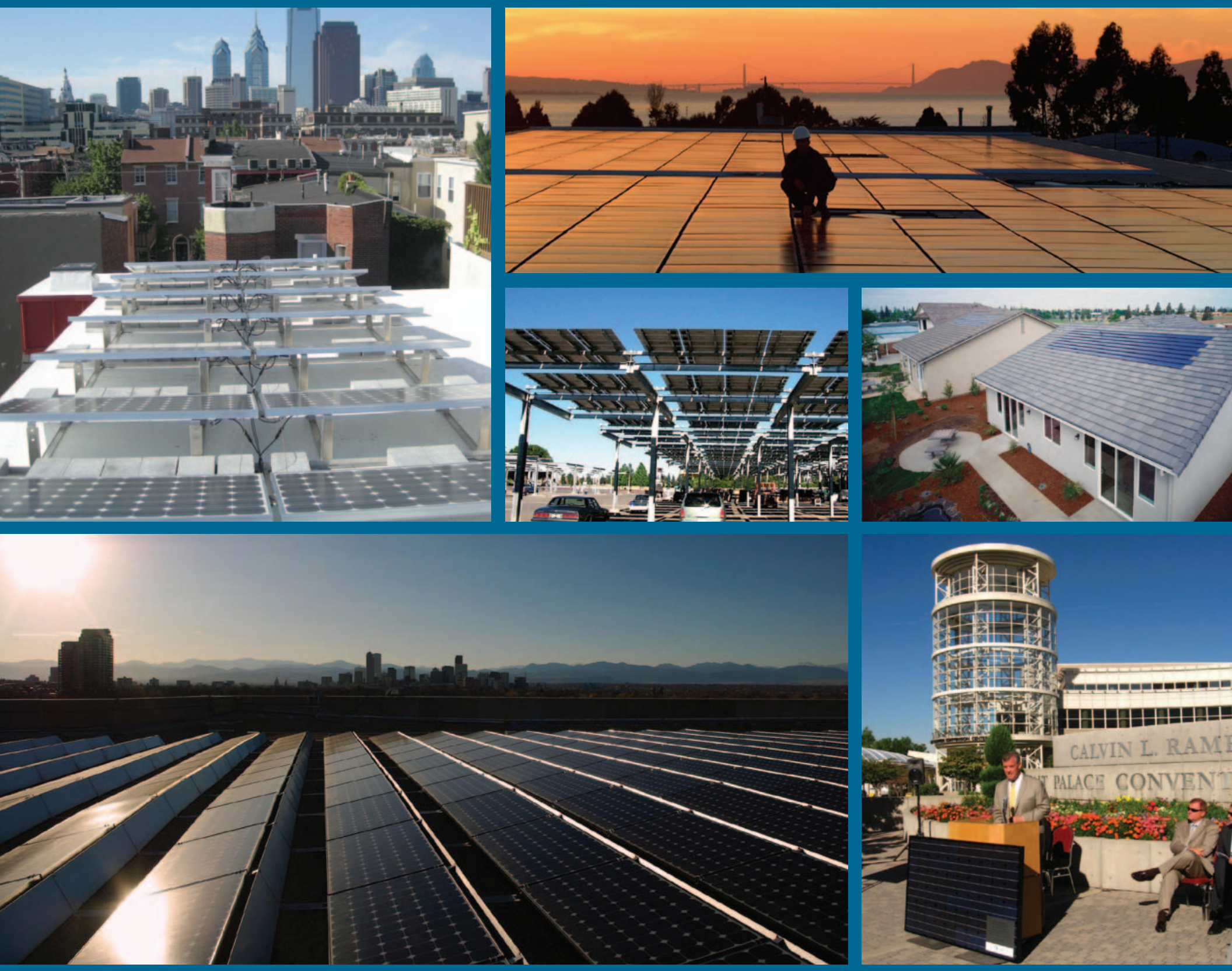

Clockwise from top left: Photovoltaic system in Philadelphia Center City district (photo from Mercury Solar Solutions); rooftop solar electric system at sunset (photo from SunPower, NREL/PIX 15279); Premier Homes development with building-integrated PV roofing, near Sacramento (photo from Premier Homes, NREL/PIX 15610); PV on Calvin L. Rampton Salt Palace Convention Center in Salt Lake City (photo from Utah Clean Energy); PV on the Denver Museum of Nature and Science (photo from Denver Museum of Nature \& Science); and solar parking structure system at the Cal Expo in Sacramento, California (photo from Kyocera Solar, NREL/PIX 09435)

\section{a ENARGY}

Energy Efficiency \& Renewable Energy
EERE Information Center

1-877-EERE-INFO (1-877-337-3463)

www.eere.energy.gov/informationcenter

Printed with a renewable-source ink on paper containing at least $50 \%$ wastepaper, including $10 \%$ post consumer waste.
Prepared by the National Renewable Energy Laboratory (NREL) NREL is a national laboratory of the U.S. Department of Energy Office of Energy Efficiency and Renewable Energy Operated by the Alliance for Sustainable Energy, LLC

DOE/GO-102011-3260 • October 2011 